\title{
Regulation of blood flow in small arteries: mechanosensory events underlying myogenic vasoconstriction
}

\author{
Kwang-Seok Hong ${ }^{1, *}$, Kijeong Kim², Michael A. Hill ${ }^{3,4}$ \\ 'Department of Physical Education, College of Education, Chung-Ang University, Seoul, Korea \\ ${ }^{2}$ School of Exercise \& Sport Science, College of Natural Sciences, University of Ulsan, Ulsan, Korea \\ ${ }^{3}$ Dalton Cardiovascular Research Center, University of Missouri-School of Medicine, Columbia, MO, USA \\ ${ }^{4}$ Department of Medical Pharmacology and Physiology, University of Missouri-School of Medicine, Columbia, MO, USA
}

As blood flow is proportional to the fourth power of the vascular radius small changes in the diameter of resistance arteries/arterioles following an increase in intraluminal pressure would be expected to substantially increase blood flow. However, arteriolar myocytes display an intrinsic ability to locally regulate blood flow according to metabolic demands by tuning the diameter of small arteries in response to local changes in hemodynamics. Critical to this, observations were made more than 100 years ago that mechanosensitive small arteries exhibit the "myogenic response" or pressure-induced vasoconstriction or vasodilation in response to increased or decreased intravascular pressure, respectively. Although cellular mechanisms underlying the myogenic response have now been studied extensively, the precise cellular mechanisms under- lying this intriguing phenomenon still remain uncertain. In particular, the biological machinery that senses changes in intravascular pressure in vascular smooth muscle cells have not been unquestionably identified and remain a significant issue in vascular biology to be fully elucidated. As such, this brief review focuses on putative mechanosensors that have been proposed to contribute to myogenic vasoreactivity. Specific attention is paid to the roles of integrins, $G$ protein-coupled receptors, and cadherins.

Keywords: Cadherins, G protein-coupled receptor, Integrins, Pressureinduced vasoconstriction/vasodilation

\section{INTRODUCTION}

Functionally active tissues typically exhibit increased metabolic demands (e.g. an accelerated glucose disappearance, high oxygen consumption) that require marked increases in blood flow. This is most evident in active skeletal muscle where the functional response is termed exercise hyperemia where blood flow can increase many folds over basal levels. Conversely, blood flow in quiescent skeletal muscle is typically relatively lower compared with highly metabolic organs including the heart, kidney, and brain. Blood flow to (non)contracting skeletal muscle is generally determined by vascular resistance. The low blood flow under resting conditions in skeletal muscle is attributed to relatively high vascular resistance/tone that results from an inherent ability of resistance arteries and arterioles to respond to changes in intravascular pressure along with sympathetic nerve activation. Specifically, vascular smooth muscle cells (VSMC) constrict when intravascular pressure increases, called myogenic vasoconstriction or pressure-induced vasoconstriction. The myogenically-active arteries and arterioles in quiescent skeletal muscle play a significant role in regulating local blood flow according to metabolic demands and maintaining appropriate blood distribution and perfusion pressure to many other organs (Clifford, 2011). Thus, an appreciation of the cellular mechanisms underlying these vasomotor responses is critical to understanding the basic functions of skeletal muscle. Further, disorders of local vascular control likely contribute to vascular pathophysiology including exercise intolerance.

While pressure-induced, myogenic, vasoconstriction in skeletal muscle resistance vessels is known to be dependent on VSMC depolarization, increased $\mathrm{Ca}^{2+}$ entry via voltage-operated calcium
${ }^{*}$ Corresponding author: Kwang-Seok Hong (D) https://orcid.org/0000-0003-4691-5807 Department of Physical Education, College of Education, Chung-Ang University, 84 Heukseok-ro, Dongjak-gu, Seoul 06974, Korea

E-mail:kshong@cau.ac.kr

Received: May 2, 2020 / Accepted: June 10, 2020
This is an Open Access article distributed under the terms of the Creative Commons Attribution Non-Commercial License (https://creativecommons.org/licenses/by-nc/4.0/) which permits unrestricted non-commercial use, distribution, and reproduction in any medium, provided the original work is properly cited. 


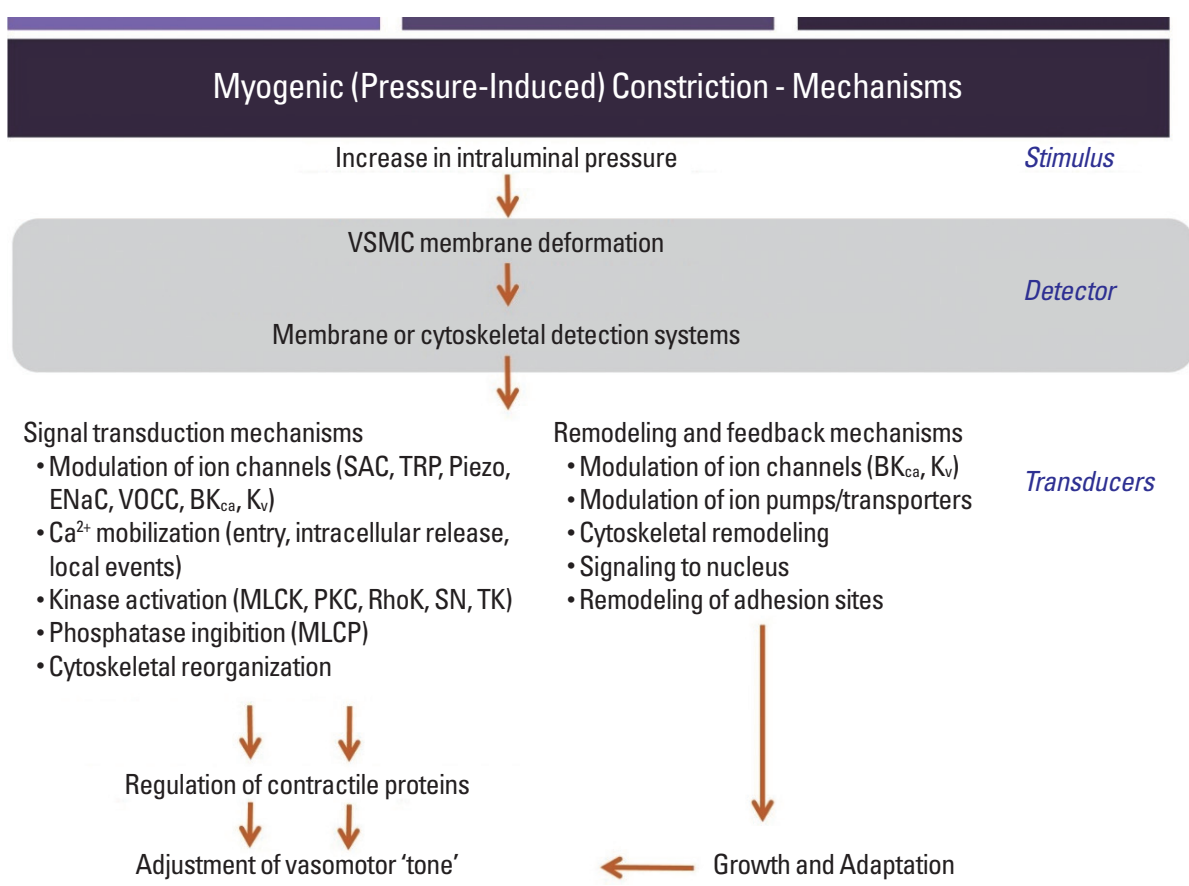

Fig. 1. Schematic diagram outlining signaling events underlying pressure-induced vasoconstriction. Mechanical stimuli on arteriolar wall generated by an increase in intraluminal pressure induce VSMC deformation (e.g., longitudinally-stretched VSMC membrane), which is detected by mechanosensitive extracellular matrix proteins, transmembrane ion channels, and receptors. The detected mechanical stimuli are transduced into biological signaling events underlying the arteriolar myogenic reactivity. Although emphasis in this paper is placed on the acute mechanosensory events, it is apparent that mechanoactivation involves a number of temporally specific events including longer-term adaptive events that may be evident as vascular remodeling. Collectively, this plasticity contributes to local blood flow control over acute and more chronic time frames. $\mathrm{BK}_{\mathrm{Ca}}$, large conductance $\mathrm{Ca}^{2+}$-activated $\mathrm{K}^{+}$channels; $\mathrm{ENaC}$, epithelial sodium channels; $\mathrm{K}_{v}$, voltage-dependent $\mathrm{K}^{+}$channels; MLCK, myosin light chain kinase; MLCP, myosin light chain phosphatase; PKC, protein kinase C; RhoK, Rho kinases; SAC, stretch-activated ion channels; TRP, transient receptor potential ion channels; VSMC, vascular smooth muscle cell.

channels and subsequent phosphorylation of the $20 \mathrm{kDa}$ myosin regulatory light chain (Fig. 1), the events or biological sensors involved in the upstream 'mechanosensation' are less clearly understood. Substantial interest has been devoted to the involvement of mechanosensitive ion channels as an underlying mechanism for initiation of depolarization (Bulley et al., 2012; Davis et al., 1992; Drummond et al., 2004; Harder, 1984; Jaggar et al., 1998; Kotecha and Hill, 2005; Welsh et al., 2002; Wu and Davis, 2001). More recently, evidence has mounted for an additional step, which suggests that classes of $G$ protein-coupled receptor (GPCR) can be activated directly by mechanical stimuli - thus not requiring their classical ligands to initiate signaling events. A further consequence of mechanically induced GPCR activation, yet to be experimentally considered, is that receptor-transactivation leads to the stimulation of pathways that regulate a number of cellular events in parallel to contraction (detailed in Fig. 1 but not substantially addressed in this brief presentation). Moreover, proteins in the extracellular matrix environment or intercellular junctions are now drawing attention as potential biological mechanosensors trans- mitting physical stress for conversion to biological events (i.e., the myogenic response) (Hill and Meininger, 2012). Thus, putative biological sensors within arteriolar myocytes are described in this review.

\section{ROLES OF INTEGRINS AND CADHERINS IN MYOGENIC CONSTRICTION}

Integrins appear as a class of strong candidate mechanosensory proteins as they provide a link between the extracellular matrix, plasma membrane, and the myocyte cytoskeleton and ultimately the contractile machinery (Fig. 2A). In effect, they are a cell-surface-adhesion receptor comprising a noncovalent association of $\alpha$ and $\beta$-subunit heterodimers. Among a variety of combinations for the heterodimers (more than 24 distinct integrins being described), the predominant species reported in arteriolar myocytes are $\alpha_{1} \beta_{1^{-}}, \alpha_{3} \beta_{1^{-}}, \alpha_{4} \beta_{1^{-}}, \alpha_{5} \beta_{1^{-}}, \alpha_{v} \beta_{1^{-}}, \alpha_{v} \beta_{3^{-}}$, and $\alpha_{v} \beta_{5}$ (Davis et al., 2001; Martinez-Lemus et al., 2005). In regard to vasomotor responses, integrin-recognizing synthetic peptides containing the 

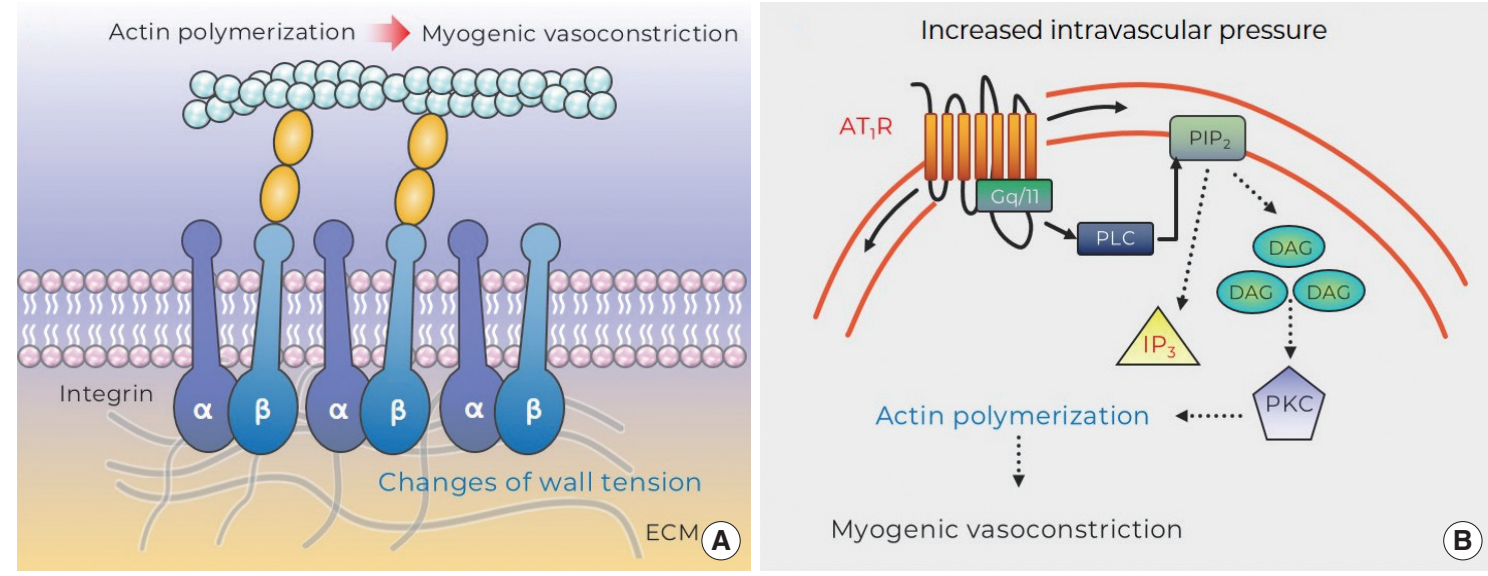

Myogenic vasoconstriction

(B)

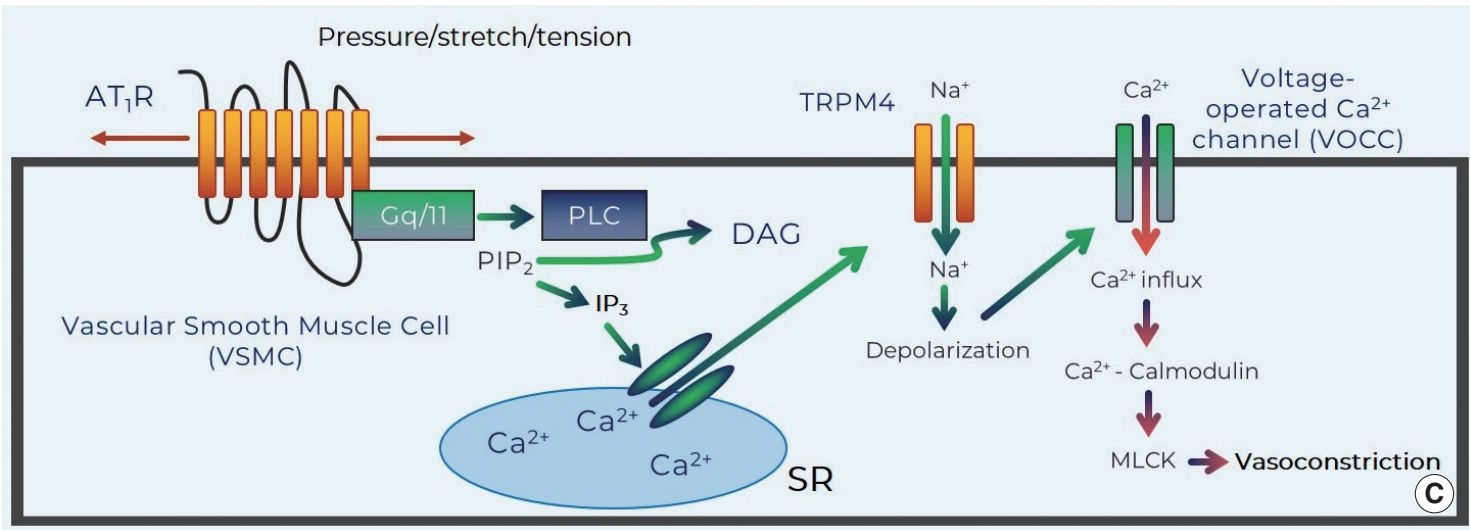

Fig. 2. Potential mechanosensors that contribute to myogenic responsiveness. (A) Changes of vascular wall tension activate integrins and evoke myogenic vasoconstriction through cytoskeleton remodeling (i.e., actin polymerization: monomeric G-actin is incorporated into F-actins). (B) Mechanosensitive AT R that senses increased intraluminal pressure generates DAG via PLC-dependent cleavage of PIP2. DAG stimulates PKC that induces actin cytoskeleton reorganization for myogenic vasoconstriction. (C) Stretch of VSMC provokes $A T_{1} R$-mediated $\mathrm{IP}_{3}$ production and subsequently results in $\mathrm{Ca}^{2+}$ release from $\mathrm{SR}$. This signaling then induces

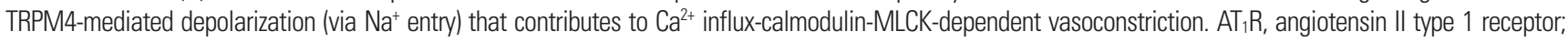
DAG, diacylglycerol; ECM, extracellular matrix; $\mathrm{IP}_{3}$, inositol trisphosphate; $\mathrm{MLCK}$, myosin light chain kinase; $\mathrm{PIP}_{2}$, phosphatidylinositol 4,5-bisphosphate; PKC, protein kinase C; PLC, phospholipase C; SR, sarcoplasmic reticulum; TRPM4, transient receptor potential melastatin member 4.

tri-peptide arginine-glycine-aspartate (RGD) induce a sustained vasodilation in rat cremaster arterioles (Mogford et al., 1996) with the RGD peptide-mediated dilation being associated with a decrease in intracellular $\mathrm{Ca}^{2+}$ (D'Angelo et al., 1997; Pierschbacher and Ruoslahti, 1987). However, the impact of RGD peptide on vascular reactivity is complex as the peptide causes vasoconstriction of rat renal afferent arterioles that appears to be mediated via an increase in intracellular $\mathrm{Ca}^{2+}$ (Yip and Marsh, 1997). Given this discrepancy studies have been undertaken to delineate the effect of integrin binding on key smooth muscle ion channels. Soluble ligands of $\alpha_{5} \beta_{1}$ integrin (i.e., RGD, fibronectin) are thus shown to lead to increased $\mathrm{Ca}^{2+}$ influx via dihydropyridine-sensitive $\mathrm{Ca}^{2+}$ channels, whereas ligand-induced activation of $\alpha_{v} \beta_{3}$ integrin reduces $\mathrm{Ca}^{2+}$ entry (Wu et al., 1998). The reciprocal $\mathrm{Ca}^{2+}$ regulation of these integrins may be related to divergent endpoint responses such as vasoconstriction or dilation. In addition to integrin-mediated direct regulation of $\mathrm{Ca}^{2+}$ influx, integrins have an ability to indirectly modulate $\mathrm{Ca}^{2+}$ signaling, vasomotor reactivity, or even myogenic responsiveness by enhancing $\mathrm{K}^{+}$efflux through large conductance $\mathrm{Ca}^{2+}$-activated $\mathrm{K}^{+}\left(\mathrm{BK}_{\mathrm{C}}\right)$ channels. Consistent with this, it has been shown that activation of $\alpha_{5} \beta_{1}$ integrin facilitates $\mathrm{BK}_{\mathrm{Ca}}$ activation via c-src-dependent phosphorylation of $\mathrm{BK}_{\mathrm{Ca}}$ (Wu et al., 2008; Yang et al., 2010). Thus, it is implied that the integ$\mathrm{rin} / \mathrm{K}^{+}$channel-induced hyperpolarization may result in inhibition of voltage-operated calcium channels and in turn alter vasomotor reactivity and/or myogenic responsiveness.

As integrins not only interact with extracellular matrix proteins including fibronectin, collagen, vitronectin, elastin, or laminin but also intracellularly provide a platform for focal adhesion proteins (Davis et al., 2001; Vuori, 1998), they serve as direct linkers 
transmitting biological signals bidirectionally between extra- and intracellular environment (i.e., outside-in and inside-out signaling) (Hill and Meininger, 2012). For example, mechanical forces (e.g., stretch or tension) exerted by increased intravascular pressure are transmitted through integrins and in turn converted to intracellular signals. An intriguing question related to the role of integrins in VSMC mechanotransduction is, do integrins participate in the myogenic response? Antibodies-blocking $\alpha_{v} \beta_{3}$ or $\alpha_{5} \beta_{1}$ integrin significantly abrogate pressure-induced vasoconstriction of rat cremaster arterioles (Martinez-Lemus et al., 2005). In addition, it has been observed that a genetic depletion of $\beta_{1}$ integrin subunit profoundly reduces vascular contractile responses to norepinephrine and high concentration extracellular $\mathrm{K}^{+}$buffer (80 $\mathrm{mmol} / \mathrm{L}$ ) in isolated superior mesenteric and femoral arteries as well as cremaster arterioles (1A-3A branches) in vivo (Turlo et al., 2013). More recently, it has been found that blockade of $\alpha_{v} \beta_{3}$ significantly decreases $\mathrm{Ca}^{2+}$ waves and pressure-induced vasoconstriction in cerebral arteries (Mufti et al., 2015). Therefore, these intriguing studies appear to support mechanosensitivity of integrins following an increase in intravascular pressure and thus their significant contribution to myogenic constriction.

In more recent studies, direct evidence has been sought for mechanisms by which pressure-induced stretch of arteriolar myocytes results in integrin adhesion and what are the underlying downstream signaling events, including tyrosine phosphorylation of the focal adhesion proteins, which mediate myogenic constriction. Such studies have been facilitated by the development of techniques such as atomic force microscopy which enables protein-protein interactions to be studied. In single arteriolar myocyte studies, contact with fibronectin (extracellular matrix protein)-coated atomic force microscopy probes results in the clustering of $\alpha_{5}$ and $\beta_{3}$ integrins, consistent with focal adhesions being formed at the cytoplasmic tails of the integrins (Sun et al., 2008). Local membrane stretch of single arteriolar myocytes, induced by controlled retraction of the atomic force microscopy probes, intriguingly gives rise to myogenic-like behaviors (i.e., a counteracting pulling-down force) that are abolished by cytochalastin $\mathrm{D}$ (an agent for actin depolymerization) or blockade of $\alpha_{5} \beta_{1}$ - and $\alpha_{v} \beta_{3}$-integrins (Sun et al., 2008). Moreover, more recent investigations, using high-sensitive Western blotting techniques, have observed that pressure-dependent stretch of cerebral arteriolar myocytes (in response to a step increase in intraluminal pressure protocol) leads to $\alpha_{5}$ integrin-mediated phosphorylation of kinase proteins within integrin adhesion complexes including focal adhesion kinase and Src family kinase (Colinas et al., 2015). The phosphor- ylation subsequently is thought to activate adhesion scaffolding (e.g., vinculin, paxillin) and signaling (e.g., phospholipase $\mathrm{C}$ gamma1) proteins. In parallel with these mechanisms, stimulation of protein kinase $\mathrm{C}$ and $\mathrm{Rho}$-associated kinase gives rise to myosin phosphatase target subunit 1-mediated $\mathrm{Ca}^{2+}$ sensitization and actin cytoskeleton rearrangement, which collectively contribute to myogenic vasoconstriction (Fig. 2A) (Colinas et al., 2015).

Emphasis has also recently been placed on cell-to-cell junctions (Hill et al., 2009; Hill and Meininger, 2012; Schwartz, 2010). Cadherins, a family of $\mathrm{Ca}^{2+}$-dependent transmembrane proteins, involves cell-to-cell interactions which are involved in a number of biological processes including embryogenesis and tissue morphogenesis (George and Beeching, 2006; Jackson et al., 2010; Takeichi, 1991). It has been demonstrated that the intracellular domain of cadherins is coupled to catenin (a scaffolding protein) and the cadherin-catenin complex is provided for a nucleation site where actin cytoskeleton remodeling occurs (Aberle et al., 1996). $\mathrm{N}$-cadherin has been shown to be the predominant cadherin expressed in rat resistance arterioles (Jackson et al., 2010; Jones et al., 2002). The question as to whether $\mathrm{N}$-cadherin detects mechanical stresses on the vascular wall and initiates intracellular signaling for pressure-induced vasoconstriction has been approached in part using specific inhibitory antibodies or synthetic tripeptides (histidine-alanine-valine) for $\mathrm{N}$-cadherin. Inhibition of $\mathrm{N}$-cadherin markedly diminishes myogenic constriction, but not intracellular $\mathrm{Ca}^{2+}$ concentration, of rat cremaster arterioles (Jackson et al., 2010). The preceding investigations raise the possibility that $\mathrm{N}$-cadherin may function as a part of the mechanosensory apparatus and be related to $\mathrm{Ca}^{2+}$ sensitization and/or cytoskeleton reorganization for the myogenic response. Indeed, it has recently been shown that adherens junctions formed by the novel mechanosensory $\mathrm{N}$-cadherin in VSMC are involved in the myogenic response in superior cerebellar arteries (Sun et al., 2017). However, as precise downstream signaling pathways have not been fully investigated, mechanistic studies are required to further understand how $\mathrm{N}$-cadherin contributes to pressure-induced vasoconstriction.

\section{INVOLVEMENT OF MECHANOSENSITIVE GPCR IN MYOGENIC CONSTRICTION}

The generally accepted concept of ligand-dependent activation of angiotensin II type 1 receptor $\left(\mathrm{AT}_{1} \mathrm{R}\right)$ has recently shifted to a new paradigm for mechanoactivation of the $\mathrm{AT}_{1} \mathrm{R}$ (i.e., ligand-independent activation) (Zou et al., 2004). There is mounting evidence showing that a number of GPCR possess inherent mecha- 
nosensitivity, thereby conceivably serving as primary biological mechanosensors that recognize membrane stretch or deformation of arteriolar myocytes caused by increased intraluminal pressure changes (Mederos y Schnitzler et al., 2008; Mederos y Schnitzler et al., 2011; Schleifenbaum et al., 2014; Storch et al., 2012; Storch et al., 2015; Yasuda et al., 2008). Supporting ligand-independent activation of GPCR, it was first demonstrated that mechanical activation of the $\mathrm{AT}_{1} \mathrm{R}$ leads to pressure overload-induced cardiac hypertrophy in the absence of angiotensin II production (Zou et al., 2004). This innovative study stimulated considerable interest in mechanisms by which the $\mathrm{AT}_{1} \mathrm{R}$ acts as a mechanosensor for initiating events associated with the myogenic response (e.g., sensation of membrane stretch or change of wall tension) and if mechanoactivation of the $\mathrm{AT}_{1} \mathrm{R}$ elicits downstream signaling pathways for pressure-induced vasoconstriction. In regard to this, it has been shown that angiotensin II-independent activation of the $\mathrm{AT}_{1} \mathrm{R}$ induced by hypotonic buffer-mediated cell swelling or positive pipette pressure increases cation influx through transient receptor potential canonical 6 channels (Mederos y Schnitzler et al., 2008). Transient receptor potential canonical 6 channels have been previously suggested to be involved in mechanosensation but are not themselves directly activated by membrane stretch (Mederos y Schnitzler et al., 2008). However, $\mathrm{AT}_{1} \mathrm{R}$ and transient receptor potential canonical 6-channel coexpression in human embryonic kidney cells results in increased cation current after application of mechanical stress (Mederos y Schnitzler et al., 2008). Thus, it is suggested that the $\mathrm{AT}_{1} \mathrm{R}$ is a key molecular mechanism for conversion of a mechanical stimulus into a biological signal.

Since the $A T_{1} R$ was identified to modulate the myogenic response, increasing emphasis has been placed on mechanistic studies relating to how mechanoactivation of the $\mathrm{AT}_{1} \mathrm{R}$ leads to myogenic constriction. It has been shown that osmotically induced membrane stretch of arteriolar myocytes reduces XE991-sensitive voltage-gated $\mathrm{K}_{\mathrm{v}}$ channel currents, but the inhibited currents are not found in the absence of the $\mathrm{AT}_{{ }_{1} \mathrm{R}} \mathrm{R}$ (Schleifenbaum et al., 2014). The $A_{1} T_{1 a} R$ mechanoactivation-mediated suppression of $\mathrm{K}^{+}$efflux via $K_{v}$ channel may be coupled to membrane depolarization and myogenic constriction (Schleifenbaum et al., 2014). Surprisingly, in this study, interplay between the $\mathrm{AT}_{1} \mathrm{R}$ and the transient receptor potential canonical 6 channels was not observed, which is inconsistent with previous studies that suggested an important role for transient receptor potential canonical 6 channels in pressureinduced vasoconstriction (Mederos y Schnitzler et al., 2008; Voets and Nilius, 2009; Welsh et al., 2002). Subsequently, in arterioles of skeletal muscle that exhibits a relatively high level of myogenic tone under resting conditions, mechanoactivation of the $\mathrm{AT}_{1} \mathrm{R}$ in response to increased intraluminal pressure was also demonstrated to induce pressure-induced vasoconstriction (Hong et al., 2016). These studies further showed that the ligand-independent activation of the $\mathrm{AT}_{1} \mathrm{R}$ activated phospholipase $\mathrm{C}$-mediated release of diacylglycerol with subsequent protein kinase $C$ downstream signaling and actin cytoskeleton remodeling and in turn myogenic vasoconstriction (Fig. 2B). Moreover, another mechanism underlying $A T_{1} R$-mediated myogenic constriction has been proposed in cerebral arteries (Gonzales et al., 2014). The mechanically activated $\mathrm{AT}_{1} \mathrm{R}$ is coupled to activation of Src tyrosine kinase that is necessary for phospholipase $\mathrm{C}$ gamma1-dependent generation of inositol trisphosphate $\left(\mathrm{IP}_{3}\right)$ and diacylglycerol. Subsequently $\mathrm{Ca}^{2+}$ release from the sarcoplasmic reticulum (by $\mathrm{IP}_{3}$-mediated activation of $\mathrm{IP}_{3} \mathrm{R}$ and calcium-induced calcium release) evokes activation of transient receptor potential melastatin 4 channels, cation entry, membrane depolarization, and myogenic constriction (Fig. 2C) (Gonzales et al., 2014). Earley and colleagues then subsequently identified that the predominant $A T_{1} R$ interacts with transient receptor potential melastatin 4 channels for myogenic responsiveness in posterior cerebral arteries (Pires et al., 2017). However, it was reported in penetrating parenchymal cerebral arterioles that the expression level of $A T_{1 a} R$ and $A T_{1 b} R$ isotype is indistinguishable and $A T_{1} R$ contributes to initiating pressure-induced vasoconstriction, but not maintaining the myogenic reactivity, in the cerebral microvasculature (Yamasaki et al., 2020).

It is well reported that GPCR superfamily is diversely expressed in arteriolar myocytes. Thus, it is likely that myogenic vasoconstriction may occur following the activation of other putative mechanosensitive GPCRs. Indeed, a variety of receptors of endothelin, muscarinic, vasopressin, histamine, bradykinin, parathyroid hormone, dopamine, and purinergic P2Y4/P2Y6 have been appreciated as potential mechanoreceptors (Abdul-Majeed and Nauli, 2001; Brayden et al., 2013; Li et al., 2014; Mederos y Schnitzler et al., 2008; Storch et al., 2012; Zhang et al., 2009). Among them, purinergic receptors have received considerable attention. Myogenic constriction of pial arteries in the cerebral circulation is sensitive to treatment with candesartan (Brayden et al., 2013), indicating that the $\mathrm{AT}_{1} \mathrm{R}$ plays an important role in myogenic constriction of the cerebral resistance arteries. However, a similar contribution of the $\mathrm{AT}_{1} \mathrm{R}$ to myogenic response has not been identified in parenchymal cerebral arterioles, whereas purinergic P2Y4 or P2Y6 receptors appear mechanosensitive and contribute to myogenic constriction of the intracerebral vessels (i.e., parenchymal arterioles) in a manner of involving transient receptor poten- 
tial melastatin 4-channel activation-dependent membrane depolarization (Brayden et al., 2013; Li et al., 2014). This suggests that pressure-induced vasoconstriction may be differentially initiated by disparate mechanosensitive GPCR in diverse vascular beds and/or species.

A novel GPCR mechanosensor, cysteinyl leukotriene 1 receptor, has been identified to participate in myogenic responsiveness (Storch et al., 2015). Activation of cysteinyl leukotriene 1 receptor has been traditionally reported to induce constriction of bronchial smooth muscle in asthma (Lynch et al., 1999; Singh et al., 2010). However, it has been found that pharmacological inhibition of cysteinyl leukotriene 1 receptor with either pranlukast or montelukast is surprisingly linked to reduced pressure-induced vasoconstriction of fourth-order mice mesenteric arterioles (Storch et al., 2015). Suppression of endogenous ligand leukotriene production using zileuton (a 5-lipoxygenase inhibitor) or a neutralizing leukotriene antibody does not influence on myogenic constriction, supporting that cysteinyl leukotriene 1 receptor is not activated by their ligand and may also play a crucial role in sensation of mechanical stresses in resistance arterioles.

One criterion for mechanoreceptors is that mechanical stimuli (i.e., tension, stretch, intraluminal pressure) are able to directly induce conformational changes of target mechanosensitive GPCR. Using a substituted cysteine accessibility mapping approach, a mechanically induced conformational change in the $A_{1} R$ has been suggested. Importantly, this change in conformation is distinct from the ligand-dependent receptor conformation (Yasuda et al., 2008). Specifically these studies showed, direct stretch (20\%) of cultured cells on extensible silicone dishes results in the seventh transmembrane protein of the $A T_{1} R$ rotating anticlockwise and dislocating towards the agonist-binding pocket of the receptor (Yasuda et al., 2008), whereas agonist-dependent activation of the $A T_{1} R$ correlates with the dislocation and rotation of the third transmembrane segment of the protein (Farrens et al., 1996; Karnik et al., 2003). Although there has not been direct evidence for the distinct conformational change of mechanically activated $\mathrm{AT}_{1} \mathrm{R}$ (e.g., crystallography studies), bioluminescence or fluorescence resonance energy transfer studies support that the $\mathrm{AT}_{1} \mathrm{R}$ favors a unique configuration (Mederos y Schnitzler et al., 2008; Rakesh et al., 2010). Therefore, the $A T_{1} R$ and other GPCR appear to have more than one active receptor conformation as shown in dynamic states of ion channels (Storch et al., 2012) and the distinct conformational changes in response ligand-mediated or mechanical stressinduced activation of the $\mathrm{AT}_{1} \mathrm{R}$ and other GPCR conceivably may confer the receptors to cause unique intracellular signaling and physiological outcomes.

An additional question relating to pressure/tension-induced activation of GPCRs is how does this mode of activation impact on their ability to signal in response to their classical ligand (i.e., in the case of the $A T_{1} R$, angiotensin II). Does mechanoactivation affect the affinity of the receptor for its agonist or does the mechanical stimulus act as a 'biased ligand' (Wang et al., 2018) activating specific elements of the signaling pathways outlined in Fig. 1? These considerations are critical for understanding the interactions that occur between local and neuroendocrine mechanisms of blood flow control.

\section{CONCLUSIONS}

Small resistance arteries play a vital role in regulating blood flow locally in response to moment-to-moment changes in intravascular pressure. Physiologically, this intrinsic autoregulatory capacity of small arteries is required, in part, to match metabolic and hemodynamic demands in tissues and organs. Such responses are particularly well developed in metabolically active tissues including brain, heart, and skeletal muscle. Meanwhile, impaired autoregulation of small arteries may contribute to diverse pathologies, including vascular rupture, capillary damage, edema, vasospasms, ischemic stroke, or hypertension. Impaired local control of blood flow may also contribute to cardiovascular dysfunction in disorders such as diabetes. Thus, investigations into how biological mechanosensors detect the circumferential forces applied on the vascular wall and how this information is exactly transduced into signaling pathways for myogenic reactivity are of potential translational relevance in regard to developing strategies for the prevention and treatment of cardiovascular diseases that result from impaired pressure-induced autoregulation. It is increasingly realized that several cellular components on arteriolar smooth muscle cells (e.g., integrins, GPCR) act as mechanotransducers and thus potentially contribute to myogenic responsiveness. For a more complete understanding of the arteriolar myogenic response, further investigations are required to integrate these observations with other components of the overall myogenic signaling mechanism including extracellular matrix proteins, ion channels, $\mathrm{Ca}^{2+}$ handling, and contractile proteins.

\section{CONFLICT OF INTEREST}

No potential conflict of interest relevant to this article was reported. 


\section{ACKNOWLEDGMENTS}

This work was supported by the Ministry of Education of the Republic of Korea and the National Research Foundation of Korea (NRF-2017S1A5B8067020).

\section{REFERENCES}

Abdul-Majeed S, Nauli SM. Dopamine receptor type 5 in the primary cilia has dual chemo- and mechano-sensory roles. Hypertension 2011; 58:325-331.

Aberle H, Schwartz H, Kemler R. Cadherin-catenin complex: protein interactions and their implications for cadherin function. J Cell Biochem 1996;61:514-523.

Brayden JE, Li Y, Tavares MJ. Purinergic receptors regulate myogenic tone in cerebral parenchymal arterioles. J Cereb Blood Flow Metab 2013;33: 293-299.

Bulley S, Neeb ZP, Burris SK, Bannister JP, Thomas-Gatewood CM, Jangsangthong W, Jaggar JH. TMEM16A/ANO1 channels contribute to the myogenic response in cerebral arteries. Circ Res 2012;111:1027-1036.

Clifford PS. Local control of blood flow. Adv Physiol Educ 2011;35:5-15.

Colinas O, Moreno-Dominguez A, Zhu HL, Walsh EJ, Perez-Garcia MT, Walsh MP, Cole WC. $\alpha 5$-Integrin-mediated cellular signaling contributes to the myogenic response of cerebral resistance arteries. Biochem Pharmacol 2015;97:281-291.

D'Angelo G, Mogford JE, Davis GE, Davis MJ, Meininger GA. Integrinmediated reduction in vascular smooth muscle $\left[\mathrm{Ca}^{2+}\right]_{\mathrm{i}}$ induced by RGD-containing peptide. Am J Physiol 1997;272:H2065-2070.

Davis MJ, Donovitz JA, Hood JD. Stretch-activated single-channel and whole cell currents in vascular smooth muscle cells. Am J Physiol 1992;262:C1083-1088.

Davis MJ, Wu X, Nurkiewicz TR, Kawasaki J, Davis GE, Hill MA, Meininger GA. Integrins and mechanotransduction of the vascular myogenic response. Am J Physiol Heart Circ Physiol 2001;280:H1427-1433.

Drummond HA, Gebremedhin D, Harder DR. Degenerin/epithelial Na+ channel proteins: components of a vascular mechanosensor. Hypertension 2004;44:643-648.

Farrens DL, Altenbach C, Yang K, Hubbell WL, Khorana HG. Requirement of rigid-body motion of transmembrane helices for light activation of rhodopsin. Science 1996;274:768-770.

George SJ, Beeching CA. Cadherin:catenin complex: a novel regulator of vascular smooth muscle cell behaviour. Atherosclerosis 2006;188:1-11.

Gonzales AL, Yang Y, Sullivan MN, Sanders L, Dabertrand F, Hill-Eubanks DC, Nelson MT, Earley S. A PLC $\gamma 1$-dependent, force-sensitive signaling network in the myogenic constriction of cerebral arteries. Sci
Signal 2014;7:ra49.

Harder DR. Pressure-dependent membrane depolarization in cat middle cerebral artery. Circ Res 1984:55:197-202.

Hill MA, Meininger GA. Arteriolar vascular smooth muscle cells: mechanotransducers in a complex environment. Int J Biochem Cell Biol 2012; 44:1505-1510.

Hill MA, Meininger GA, Davis MJ, Laher I. Therapeutic potential of pharmacologically targeting arteriolar myogenic tone. Trends Pharmacol Sci 2009;30:363-374.

Hong K, Zhao G, Hong Z, Sun Z, Yang Y, Clifford PS, Davis MJ, Meininger GA, Hill MA. Mechanical activation of angiotensin II type 1 receptors causes actin remodelling and myogenic responsiveness in skeletal muscle arterioles. J Physiol 2016;594:7027-7047.

Jackson TY, Sun Z, Martinez-Lemus LA, Hill MA, Meininger GA. N-cadherin and integrin blockade inhibit arteriolar myogenic reactivity but not pressure-induced increases in intracellular Ca. Front Physiol 2010; 1:165.

Jaggar JH, Wellman GC, Heppner TJ, Porter VA, Perez GJ, Gollasch M, Kleppisch T, Rubart M, Stevenson AS, Lederer WJ, Knot HJ, Bonev $\mathrm{AD}$, Nelson MT. $\mathrm{Ca}^{2+}$ channels, ryanodine receptors and $\mathrm{Ca}^{2+}$-activated $\mathrm{K}^{+}$channels: a functional unit for regulating arterial tone. Acta Physiol Scand 1998;164:577-587.

Jones M, Sabatini PJ, Lee FS, Bendeck MP, Langille BL. N-cadherin upregulation and function in response of smooth muscle cells to arterial injury. Arterioscler Thromb Vasc Biol 2002;22:1972-1977.

Karnik SS, Gogonea C, Patil S, Saad Y, Takezako T. Activation of G-protein-coupled receptors: a common molecular mechanism. Trends Endocrinol Metab 2003;14:431-437.

Kotecha N, Hill MA. Myogenic contraction in rat skeletal muscle arterioles: smooth muscle membrane potential and $\mathrm{Ca}^{2+}$ signaling. Am J Physiol Heart Circ Physiol 2005;289:H1326-1334.

Li Y, Baylie RL, Tavares MJ, Brayden JE. TRPM4 channels couple purinergic receptor mechanoactivation and myogenic tone development in cerebral parenchymal arterioles. J Cereb Blood Flow Metab 2014;34: 1706-1714.

Lynch KR, O’Neill GP, Liu Q, Im DS, Sawyer N, Metters KM, Coulombe N, Abramovitz M, Figueroa DJ, Zeng Z, Connolly BM, Bai C, Austin CP, Chateauneuf A, Stocco R, Greig GM, Kargman S, Hooks SB, Hosfield E, Williams DL Jr, Ford-Hutchinson AW, Caskey CT, Evans JF. Characterization of the human cysteinyl leukotriene CysLT1 receptor. Nature 1999;399:789-793.

Martinez-Lemus LA, Crow T, Davis MJ, Meininger GA. $\alpha v \beta 3$ - and $\alpha 5 \beta 1$ integrin blockade inhibits myogenic constriction of skeletal muscle resistance arterioles. Am J Physiol Heart Circ Physiol 2005;289:H322-329. Mederos y Schnitzler M, Storch U, Gudermann T. AT1 receptors as mech- 
anosensors. Curr Opin Pharmacol 2011;11:112-116.

Mederos y Schnitzler M, Storch U, Meibers S, Nurwakagari P, Breit A, Es$\sin \mathrm{K}$, Gollasch M, Gudermann T. Gq-coupled receptors as mechanosensors mediating myogenic vasoconstriction. EMBO J 2008;27:30923103.

Mogford JE, Davis GE, Platts SH, Meininger GA. Vascular smooth muscle $\alpha \mathrm{v} \beta 3$ integrin mediates arteriolar vasodilation in response to RGD peptides. Circ Res 1996;79:821-826.

Mufti RE, Zechariah A, Sancho M, Mazumdar N, Brett SE, Welsh DG. Implications of $\alpha v \beta 3$ integrin signaling in the regulation of $\mathrm{Ca}^{2+}$ waves and myogenic tone in cerebral arteries. Arterioscler Thromb Vasc Biol 2015;35:2571-2578.

Pierschbacher MD, Ruoslahti E. Influence of stereochemistry of the sequence Arg-Gly-Asp-Xaa on binding specificity in cell adhesion. J Biol Chem 1987;262:17294-17298.

Pires PW, Ko EA, Pritchard HAT, Rudokas M, Yamasaki E, Earley S. The angiotensin $\mathrm{II}$ receptor type $1 \mathrm{~b}$ is the primary sensor of intraluminal pressure in cerebral artery smooth muscle cells. J Physio 2017;595: 4735-4753.

Rakesh K, Yoo B, Kim IM, Salazar N, Kim KS, Rockman HA. $\beta$-Arrestinbiased agonism of the angiotensin receptor induced by mechanical stress. Sci Signal 2010;3:ra46.

Schleifenbaum J, Kassmann M, Szijarto IA, Hercule HC, Tano JY, Weinert S, Heidenreich M, Pathan AR, Anistan YM, Alenina N, Rusch NJ, Bader M, Jentsch TJ, Gollasch M. Stretch-activation of angiotensin II type 1a receptors contributes to the myogenic response of mouse mesenteric and renal arteries. Circ Res 2014;115:263-272.

Schwartz MA. Integrins and extracellular matrix in mechanotransduction. Cold Spring Harb Perspect Biol 2010;2:a005066.

Singh RK, Gupta S, Dastidar S, Ray A. Cysteinyl leukotrienes and their receptors: molecular and functional characteristics. Pharmacology 2010;85:336-349.

Storch U, Blodow S, Gudermann T, Mederos y Schnitzler M. Cysteinyl leukotriene 1 receptors as novel mechanosensors mediating myogenic tone together with angiotensin II type 1 receptors-brief report. Arterioscler Thromb Vasc Biol 2015;35:121-126.

Storch U, Mederos y Schnitzler M, Gudermann T. G protein-mediated stretch reception. Am J Physiol Heart Circ Physiol 2012;302:H12411249.

Sun Z, Li M, Li Z, Hill MA, Meininger GA. N-cadherin, a novel and rapidly remodelling site involved in vasoregulation of small cerebral arteries. J. Physiol 2017;595:1987-2000.

Sun Z, Martinez-Lemus LA, Hill MA, Meininger GA. Extracellular matrix-specific focal adhesions in vascular smooth muscle produce mechanically active adhesion sites. Am J Physiol Cell Physiol 2008;295:

\section{C268-278.}

Takeichi M. Cadherin cell adhesion receptors as a morphogenetic regulator. Science 1991;251:1451-1455.

Turlo KA, Scapa J, Bagher P, Jones AW, Feil R, Korthuis RJ, Segal SS, Iruela-Arispe ML. beta1-integrin is essential for vasoregulation and smooth muscle survival in vivo. Arterioscler Thromb Vasc Biol 2013;33:23252335.

Voets T, Nilius B. TRPCs, GPCRs and the Bayliss effect. EMBO J 2009;28: 4-5.

Vuori K. Integrin signaling: tyrosine phosphorylation events in focal adhesions. J Membr Biol 1998;165:191-199.

Wang J, Hanada K, Gareri C, Rockman HA. Mechanoactivation of the angiotensin II type 1 receptor induces $\beta$-arrestin-biased signaling through Gai coupling. J Cell Biochem 2018;119:3586-3597.

Welsh DG, Morielli AD, Nelson MT, Brayden JE. Transient receptor potential channels regulate myogenic tone of resistance arteries. Circ Res 2002;90:248-250.

Wu X, Davis MJ. Characterization of stretch-activated cation current in coronary smooth muscle cells. Am J Physiol Heart Circ Physiol 2001; 280:H1751-1761.

Wu X, Mogford JE, Platts SH, Davis GE, Meininger GA, Davis MJ. Modulation of calcium current in arteriolar smooth muscle by $\alpha v \beta 3$ and a5ß1 integrin ligands. J Cell Biol 1998;143:241-252.

Wu X, Yang Y, Gui P, Sohma Y, Meininger GA, Davis GE, Braun AP, Davis MJ. Potentiation of large conductance, $\mathrm{Ca}^{2+}$-activated $\mathrm{K}^{+}(\mathrm{BK})$ channels by $\alpha 5 \beta 1$ integrin activation in arteriolar smooth muscle. J Physiol 2008;586:1699-1713.

Yamasaki E, Thakore P, Krishnan V, Earley S. Differential expression of angiotensin II type 1 receptor subtypes within the cerebral microvasculature. Am J Physiol Heart Circ Physiol 2020;318:H461-469.

Yang Y, Wu X, Gui P, Wu J, Sheng JZ, Ling S, Braun AP, Davis GE, Davis MJ. $\alpha 5 \beta 1$ integrin engagement increases large conductance, $\mathrm{Ca}^{2+}$-activated $\mathrm{K}^{+}$channel current and $\mathrm{Ca}^{2+}$ sensitivity through c-src-mediated channel phosphorylation. J Biol Chem 2010;285:131-141.

Yasuda N, Miura S, Akazawa H, Tanaka T, Qin Y, Kiya Y, Imaizumi S, Fujino M, Ito K, Zou Y, Fukuhara S, Kunimoto S, Fukuzaki K, Sato T, Ge J, Mochizuki N, Nakaya H, Saku K, Komuro I. Conformational switch of angiotensin II type 1 receptor underlying mechanical stressinduced activation. EMBO Rep 2008;9:179-186.

Yip KP, Marsh DJ. An Arg-Gly-Asp peptide stimulates constriction in rat afferent arteriole. Am J Physiol 1997;273:F768-776.

Zhang YL, Frangos JA, Chachisvilis M. Mechanical stimulus alters conformation of type 1 parathyroid hormone receptor in bone cells. Am J Physiol Cell Physiol 2009;296:C1391-1399.

Zou Y, Akazawa H, Qin Y, Sano M, Takano H, Minamino T, Makita N, 
Iwanaga K, Zhu W, Kudoh S, Toko H, Tamura K, Kihara M, Nagai T,

Fukamizu A, Umemura S, Iiri T, Fujita T, Komuro I. Mechanical stress activates angiotensin II type 1 receptor without the involvement of angiotensin II. Nat Cell Biol 2004;6:499-506. 